\title{
Yığma Yapılarda Kullanılan Kenetlerin Yapı Davranışına Etkilerinin İncelenmesi
}

\author{
Tülin ÇELIK ${ }^{1}$, Şükran TANRIVERDi ${ }^{1}{ }^{*}$, Ali URAL ${ }^{1}$, Fatih Kürşat FIRAT ${ }^{1}$ \\ ${ }^{1}$ Aksaray Üniversitesi, Mühendislik Fakültesi, Inş̧at Mühendisliği Bölümü, Aksaray \\ Sorumlu yazar e-posta: sukran_tugrulelci@hotmail.com ORCID ID: https://orcid.org/0000-0001-9751-5788 \\ tulinsandikci@gmail.com \\ uralali@gmail.com \\ https://orcid.org/0000-0001-8638-9579 \\ https://orcid.org/0000-0001-8674-6169 \\ fkfirat@gmail.com \\ https://orcid.org/0000-0003-0508-2845
}

Geliş Tarihi: 04.02.2021 Kabul Tarihi: 26.06.2021

Öz

\begin{abstract}
Kültürel mirasımızın önemli bir parçası olan tarihi yapılar, zaman içerisinde iklim şartları ve insan etkilerinden kaynaklanan yapısal bozulma, hasar ve yıkılmalara maruz kalmıştır. Tarihi yapıların yapısal bütünlüklerini koruyarak gelecek nesillere güvenli bir şekilde aktarmak temel amaçlarımız arasında yer almalıdır. Tarihi yapıların onarım ve güçlendirilmesinde aslına uygun malzeme ve uygun onarım ve güçlendirme teknikleri kullanılması gerekmektedir. Tarihi yapılarda en yaygın kullanılan onarım ve güçlendirme yöntemi kenet ve zıvanalardır. Yapılan çalışmada, kenetlerin batma noktasının taşın kenarına olan mesafesi dikkate alınmış ve kenetlerin taşın kayma dayanımı üzerindeki etkisi deneysel ve sayısal olarak incelenmiştir. Bu kapsamda deneysel çalışma laboratuvarda gerçekleştirilmiş olup sayısal çalışmada 3 boyutlu modeli oluşturmak için sonlu elemanlar yöntemini (SEY) esas alan LUSAS yazılımı kullanılmıştır. Yapılan deney ve analiz sonuçlarına göre, taş kenarı ile batma noktası arasındaki mesafe incelenmiş ve bunların taşlar üzerindeki etkileri karşılaştırılarak incelenip, birtakım önerilerde

bulunulmuştur.
\end{abstract}

Anahtar kelimeler

Kenet;

Tarihi yapılar;

LUSAS;

Çekme gerilmesi;

Kayma dayanımı

\section{Investigation of the Effects of Clamps Used in Masonry Structures on Building Behavior}

\begin{tabular}{cl} 
& Abstract \\
\cline { 2 - 3 } & Historical structures, which are an important part of our cultural heritage, have been exposed to \\
structural deterioration, damage and destruction caused by climatic conditions and human effects over \\
time. Preserving the structural integrity of historical structures and transferring them to hand down the \\
Keywords & next generations safely should be among our main aims. In order to repair and strengthen historical \\
buildings, it is necessary to use original materials and appropriate repair and strengthening techniques. \\
Historical structures; \\
LUSAS;
\end{tabular}$\quad \begin{aligned} & \text { The most widely used method of repair and strengthening in historical buildings is clamps and dowels. } \\
& \text { In this study, the distance between the edge of the stone and immersion point of clamps was taken into } \\
& \text { Shear strength }\end{aligned} \quad \begin{aligned} & \text { account as variant parameter and the influence of the clamps on the shear strength of the stone are } \\
& \text { investigated experimentally and numerically. In this context, the experimental study was carried out in } \\
& \text { the laboratory and the LUSAS software based on the finite element method (FEM) was used to create } \\
& \text { a 3D model. According to the results of the experiments and analysis, the optimum distance between } \\
& \text { the edge of the stone and the immersion points are examined and some suggestions were made by } \\
& \text { comparing their effects on the stones. }\end{aligned}$

(c) Afyon Kocatepe Üniversitesi

\section{Giriş}

Eski dönemlerde yapılan ve günümüze kadar gelebilen tarihi yapılar toplumların hayatını, kültürünü, inancını ve bulunduğu dönemin özelliklerini bizlere anlatan eserlerdir. Anadolu coğrafyasında insanlar ihtiyaçlarını karşılamak için cami, tekke, imaret, medrese, han, hamam, köprü, su kemeri, saray ve kale gibi birçok farklı yapı inşa etmiştir. Bu tarihi yapılar gerek doğal felaketlerden 
gerekse insan kaynaklı etkenlerden dolayı hasar görmüşlerdir. Birçok tarihi yapı, çevresel ve insan kaynaklı olumsuz etkenlere ve zamanın etkilerine karşı koyarak ayakta kalabilmeyi başarmıştır. Anadolu'da bulunan birçok tarihi yapı taş ve tuğla gibi malzemelerden inşa edilmiştir. $\mathrm{Bu}$ tür malzemeler kullanılarak yapılan tarihi yapıların basınç dayanımı yüksek, çekme dayanımları ise düşüktür.

Tarihi yapılar düşük çekme dayanımlarına sahip olması sebebiyle yapıya gelen deprem gibi yatay kuvvetleri karşılayamadıkları için bu yapılar hasar görmekte ya da yıkılmaktadır. Bu tür yapılarda sünekliliği artıracak herhangi bir malzeme kullanılmaması nedeniyle dinamik etkiler altında gevrek bir davranış sergileyerek hasar görmektedir. Bu sebeplerden dolayı birçok donatısız tarihi yapı, onarım ve güçlendirmeye ihtiyaç duymaktadır. Deprem gibi yatay kuvvetler karşısında yapı sisteminin bütünlük içinde hareket etmesi oldukça önemlidir. Tarihi yapıya gelen yatay kuvvetlere karşı, yapı sisteminin kayma kuvvetine karşı dayanımı oldukça düşük olması nedeniyle yapının bütünlüğü korunamamaktadır.

Tarihi yapıların yatay kuvvetlere karşı stabilitesini arttırmak amacıyla kenet ve zıvana gibi metal bağlantı elemanları kullanılmaktadır. Günümüzde litaratürde yapılan çalışmalar incelendiğinde kenetlerin yığma yapı sistemi üzerine olumlu etkileri olduğu görülmüştür.

Baranaydın (2020), Ephesos St. Jean Kilisesi'nde 100 yıldır devam eden, geçmişte ve günümüzde yapılan restorasyon ve konservasyon tekniklerini, sonuçlarını, farklııklarını ve benzerliklerini incelemiştir. Ephesos St. Jean Kilisesi'nde geniş boşluklu çatlakların onarımında demir kenet ile dikiş uygulamasının yapıldığı, kullanılan malzemelerin hatalı olması nedeniyle, uzun vadede yapısal sıkıntılara yol açtığına değinilmiştir. Yılmaz ve Tek (2018), Antalya Yivli minare ve camisinin mevcut durumunu inceleyerek cami ve minarede oluşan hasarları tespit etmişlerdir. Bu çalışmada elde edilen sonuçların ve verilerin değerlendirmesi yapılarak yapılardaki hasarları gidermek amacıyla restorasyon ve güçlendirme önerileri geliştirmişlerdir. Minare gövdesindeki yapısal çatlakların onarılması ve beden duvarlarının güçlendirilmesi amacıyla metal kenetler ile dikiş uygulaması yapılmasını önermişlerdir. Tanrıverdi (2018), çalışmada metal bağlantı elemanı olan kenetlerin, yığma taş blokların davranışlarına etkisini deneysel yöntemler kullanarak incelemiştir. Yapılan deneysel çalışma sonucunda değişken olarak kenet demirlerinin yığma taş blok üzerindeki batma derinliği dikkate alınarak optimum batma derinliği bulunmuştur. Kurugöl ve Küçük (2015), çalışmasında tarih boyunca kullanılan demir malzemesinin, geleneksel mimarideki uygulama alanı ve uygulanma biçimleri ele alınarak, üretim teknikleri ve şekil verme yöntemlerini incelemiştir. Çalışmasında zaman içerisinde meydana gelen problemler ortaya konulmuştur. Ural vd. (2015) çalışmasında, aynı boyuttaki yığma duvar numuneleri ile farklı kenetzıvana sistemlerinin uygulanması ile gerçekleştirilen deneylerin sonuçları incelenmiştir. Yapılan bu çalışma ile uygulanan sistemlerin, yığma duvarların kayma kapasitesine olan etkisi incelenmiş ve önerilerde bulunulmuştur. Smoljanovic vd. (2015), kenet ve zıvanalar ile güçlendirilmiş taş yığma yapıların analizi sonlu elemanlar metodunu kullanarak yapılan çalışmada çelik kenet ve çelik zıvanalar ile güçlendirilen tarihi yığma yapının, sonlu elemanlar yöntemi ile sismik performansını tahmin etmişlerdir. Karabörk ve Koçak (2014), taş duvarlarının kesme mukavemetini artıran yeni metal bağlantı elemanları üzerinde kayma testleri yapmışlardır. Çeşitli bağlantı tasarımları ile üç farklı metal bağlantı elemanı, kayma dayanımı altında test edilmiştir. Yeni kenetlerin, duvar numuneleri üzerinde kesme mukavemetini ve sünekliğini etkili bir şekilde arttırdığını öne sürmüşlerdir. Uslu, (2013), Yaptığı çalışmada, metal bağlantı elemanları kullanılarak örülen yığma duvarlar üzerinde deneysel çalışmalar yapmıştır. Metal bağlantı elemanları olarak kenet ve zıvana kullanılmıştır. Deneysel çalışmada, yığma duvar numunelerini diyagonal basınç etkisine tabi tutarak duvarların kesme etkisindeki davranışlarını incelemiştir. Numuneler kırılma yüklerine ve kesme dayanımlarına göre değerlendirmeye alınmıştır. Kenet ve zıvanalar ile yapılan yığma duvarların bağlantı elemanı kullanılmayan taş yığma duvara göre daha yüksek dayanım gösterdiği sonucuna ulaşmışlardır. 
Bu çalışma kapsamında genişliği ve batma derinliği aynı olan kenetlerin taşın kenarına olan mesafesinin yığma taşın kayma dayanımı üzerindeki etkisi deneysel ve sayısal analiz yöntemleri ile incelenmiştir. Deney ve analiz sonuçları birbirleri ile karşılaştırılarak minimum kenet batma derinliğinin taşın kenarına olan mesafesi belirlenmiştir.
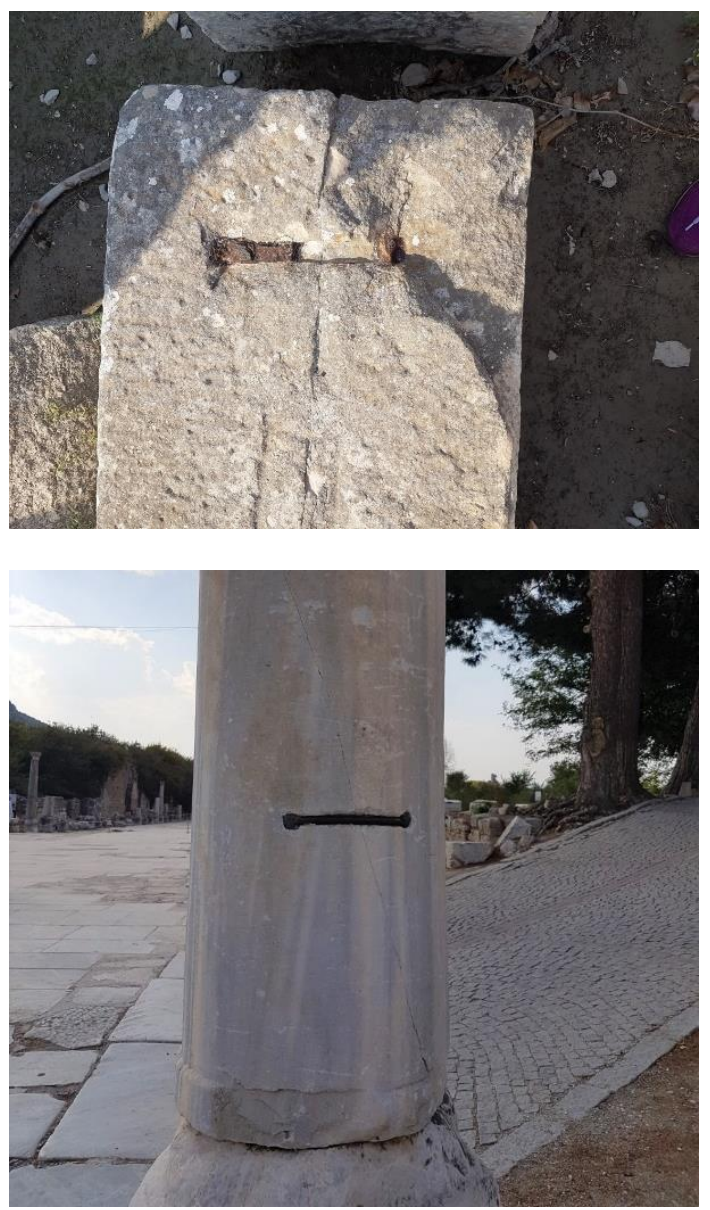

Şekil 1. Artemis Tapınağı'nda bulunan yığma taş bloklar üstündeki kenet uygulamaları.

\section{Materyal ve Metot}

Çalışmada Aksaray illi'nde bulunan Sevinçli Kasabasında çıkarılan volkanik kökenli tüf taşı kullanılmıştır. Yığma yapılarda kullanılan taşların basınç dayanımları yüksek, çekme dayanımları düşüktür. Deneyde kullanılan taşların da bu özellikleri yansıtması gerekmektedir. Taşın ve kenetin malzeme özelliklerini belirlemek amacıyla Aksaray Üniversitesi Mühendislik Fakültesi Yapı Mekaniği Laboratuvarında malzeme deneyleri yapılmıştır. Volkanik kökenli tüf taşı için basınç dayanım testi, eğilmede çekme dayanım testi; kenet için ise çekme testi yapılmıştır. Taşın basınç dayanım testi, TS EN 772-1+A1 (2015) (Kagir birimlerin basınç dayanımının tayini) dikkate alınarak yapılmıştır. Standartta belirtildiği gibi $50 \times 50 \times 50 \mathrm{~mm}^{3}$ ebatında toplamda 6 adet tüf taşı üzerinde basınç dayanım testleri yapılmıştır. Çizelge 1'de volkanik kökenli tüf taşının basınç dayanım test sonuçları verilmiştir. Deney sonucunda taşın ortalama basınç dayanım sonucu 4,13 MPa ve standart sapması 0,66 MPa elde edilmiştir.

Taşın eğilmede çekme dayanımını belirlemek amacıyla TS EN 772-6 (2004) (Beton kâgir birimlerin eğilmede çekme dayanımının tayini) dikkate

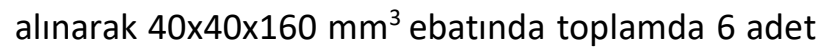
tüf taşı üzerinde testler yapılmıştır. Eğilmede çekme dayanım test sonucunda taşın ortalama çekme dayanımı Çizelge 2' de verildiği gibi $0,71 \mathrm{MPa}$ olarak elde edilmiştir.

Çizelge 1. Volkanik kökenli tüf taşının basınç dayanım test sonuçları.

\begin{tabular}{ccccc}
\hline $\begin{array}{c}\text { Numune } \\
\text { No }\end{array}$ & $\begin{array}{c}\text { En kesit boyutları } \\
(\mathbf{m m})\end{array}$ & $\begin{array}{c}\text { Kırılma Yükü } \\
\mathbf{( N )}\end{array}$ & $\begin{array}{c}\text { Basınç } \\
\text { Dayanımı } \\
\text { (MPa) }\end{array}$ \\
\cline { 2 - 3 } A1 & 52 & 51 & 12650 & 5,06 \\
\hline A2 & 50 & 50 & 10850 & 4,34 \\
\hline A3 & 50 & 50 & 8570 & 3,43 \\
\hline A4 & 50 & 48 & 9970 & 3,98 \\
\hline A5 & 52 & 50 & 11450 & 4,58 \\
\hline A6 & 51 & 53 & 8450 & 3,38 \\
\hline & & & Ortalama & 4,13 \\
\hline & & Standart & 0,66 \\
& & & Sapma & \\
\hline
\end{tabular}

Çizelge 2. Volkanik kökenli tüf taşının eğilmede çekme dayanım test sonuçları.

\begin{tabular}{ccc}
\hline Numune No & $\begin{array}{c}\text { Kırılma Yükü } \\
\text { (N) }\end{array}$ & $\begin{array}{c}\text { Basınç Dayanımı } \\
\text { (MPa) }\end{array}$ \\
\hline A1 & 490 & 0,77 \\
\hline A2 & 490 & 0,62 \\
\hline A3 & 560 & 0,88 \\
\hline A4 & 500 & 0,68 \\
\hline A5 & 450 & 0,59 \\
\hline A6 & 570 & 0,72 \\
\hline & Ortalama & 0,71 \\
\hline
\end{tabular}

TS EN ISO 6892-1 (2020) (Metalik Malzemeler Çekme Deneyi) standartı dikkate alınarak, deneyde kullanılan kenetin çekme dayanımı testi yapılmıştır. Çekme dayanımları standartta belirtildiği gibi Denklem 1 ile hesaplanmıştır. 
$R m=F m$

$\mathrm{R}_{\mathrm{m}}$ : Çekme dayanımı, $\mathrm{F}_{\mathrm{m}}$ ise deney sırasında akmanın gerçekleşmesi öncesinde numunenin dayandığı en büyük yüktür. Kenet numunelerin çekme dayanımları deney sonucunda yaklaşık olarak 290 MPa bulunmuştur.

\section{Deneysel Çalışma}

Yapılan çalışmada kenetin batma noktasının tüf taşının kenarına olan mesafesi dikkate alınarak kenetin yığma taşın kayma dayanımı üzerindeki etkisi deneysel ve sayısal olarak araştırılmıştır. Deneyde ve analizde kullanılan tüf taşının ve kenet modelinin boyutları Şekil 2'de verilmiştir. Şekilde de belirtildiği gibi tüf taşının boyutları 100x100×200 $\mathrm{mm}^{3}$ tür.

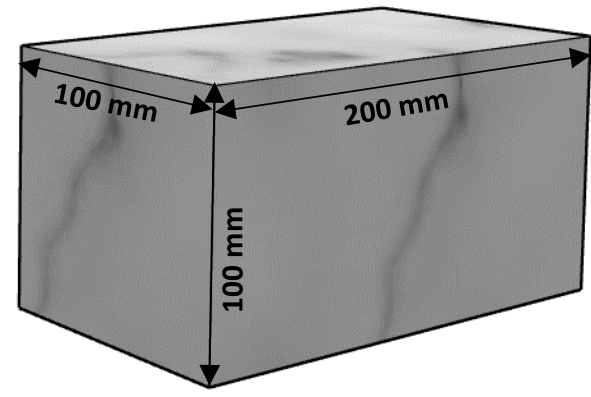

(a)

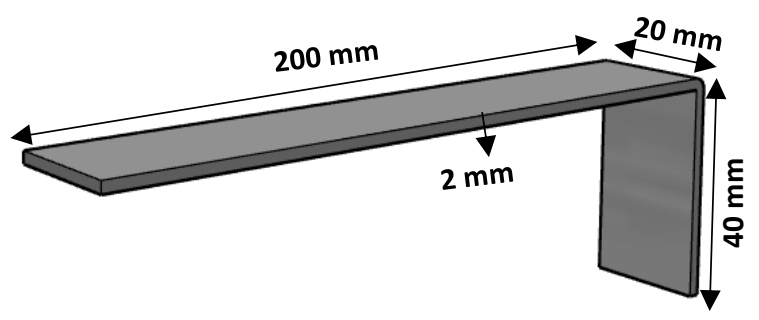

(b)

Şekil 2. a) Yığma taş boyutları, (b) Kenet modelinin boyutları.

Çalışmada kenetin genişliği $20 \mathrm{~mm}$, batma derinliği $40 \mathrm{~mm}$ alınırken, değişken olarak ele alınan kenetin batma noktasının taşın kenarına olan uzaklığı Çizelge 3 'de belirtildiği gibi $20 \mathrm{~mm}, 40 \mathrm{~mm}, 60 \mathrm{~mm}, 80 \mathrm{~mm}$ ve $100 \mathrm{~mm}$ olarak ele alınmıştır. Kenet modelinin tüf taşı üzerine yerleştirilmiş şekli ve deney düzeneği Şekil 3'de gösterildiği gibidir.
Çizelge 3. Hazırlanan modellerin geometrik özellikleri.

\begin{tabular}{ccccc}
\hline Model No & L (mm) & $\mathbf{a}(\mathbf{m m})$ & $\mathbf{b}(\mathbf{m m})$ & $\mathbf{h}(\mathbf{m m})$ \\
\hline 1 & & & 20 \\
\hline 2 & & & & 40 \\
\hline 3 & 40 & 100 & 200 & 60 \\
\hline 5 & & & & 100 \\
\hline
\end{tabular}

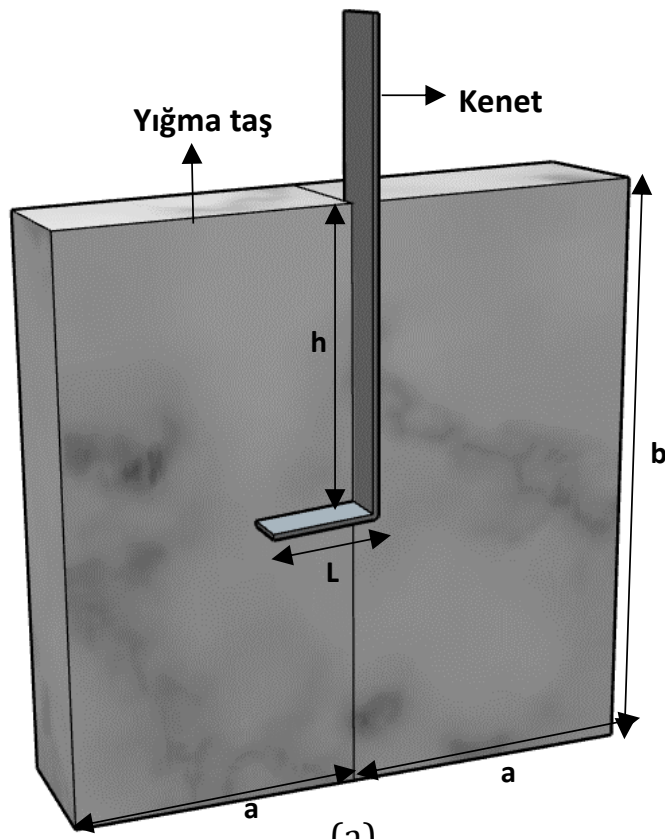

(a)

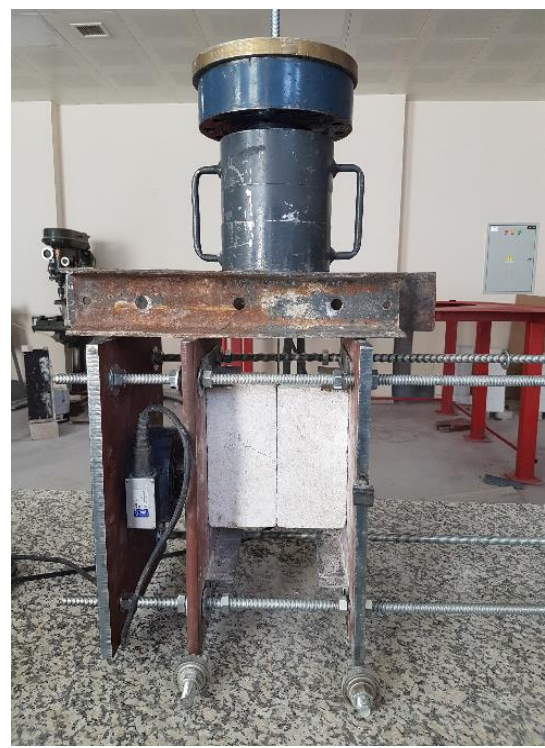

(b)

Şekil 3. (a) Kenet uygulamasının yerleştirilmesi, (b) Deney düzeneği.

Yapılan deneysel çalışma TS EN 1052-3 (2004) (Kâgir deney metotları) standartına uygun olarak hazırlanan deney düzeneğinde gerçekleştirilmiştir. Şekil 3'de de belirtildiği gibi $300 \times 400 \mathrm{~mm}^{2}$ 
boyutlarında $15 \mathrm{~mm}$ kalınlığındaki üç adet çelik plakalar, $50 \mathrm{~mm}$ uzaklıkta boşluklar açılarak köşelerinden çapı $16 \mathrm{~mm}$ olan tij demirleri ile birbirlerine bağlanmıştır. 10 tonluk yük hücresi eksenel yükü okuyabilmek amacıyla iki çelik plaka arasına yerleştirilmiştir. Standartta belirtildiği gibi yığma birimlerin basınç dayanımı $10 \mathrm{MPa}$ dan küçük olması durumunda eksenel basınç yükleri 0,1 MPa, 0,3 MPa ve 0,5 MPa olacak şekilde numunelere uygulanmalıdır. Eksenel basınç yükleri numuneye, tij demirlerine bağlı olan bulonların sıkılmasıyla çelik plakaların hareket etmesi sağlanarak verilmektedir. Deneyde kullanılan tüf taşının basınç dayanımı 4,13 MPa olması sebebiyle 0,5 MPa'lık eksenel basınç yükü verilmiştir. Numuneler üzerinde istenilen eksenel basınç yükü sağlandığı zaman, deney düzeneği üzerine hidrolik pompa ve 50 ton kapasiteye sahip yük hücresi ile kayma yükü verilmiştir. Deney düzeneğine yer değiştirmeleri ölçmek amacıyla LVDT (Linear Variable Differential Transformer) bağlanmıştır. Her bir numuneden en az üç tane yapılarak toplamda 15 adet numune deneye tabi tutulmuştur. Şekil 4'de gösterildiği gibi $100 \times 100 \times 200 \mathrm{~mm}^{3}$ boyutlarındaki tüf taşına, $20 \mathrm{~mm}$ genişliğinde, $40 \mathrm{~mm}$ batma derinliği olan kenetin batma derinliğinin kenara olan mesafeleri $20 \mathrm{~mm}$, $40 \mathrm{~mm}, 60 \mathrm{~mm}, 80 \mathrm{~mm}$ ve $100 \mathrm{~mm}$ olacak şekilde matkap yardımı ile boşluklar açılmıştır. $20 \mathrm{~mm}$ genişliğinde $2 \mathrm{~mm}$ kalınlığında kenetler bu boşluklara yerleştirilmiştir. Şekilde görüldüğü gibi diğer tüf taşı üzerine de $20 \mathrm{~mm}$ genişliğinde $2 \mathrm{~mm}$ kalınlığında ve kenetin batma derinliğinin taşın kenarına olan mesafesi $20 \mathrm{~mm}, 40 \mathrm{~mm}, 60 \mathrm{~mm}, 80$ $\mathrm{mm}$ ve $100 \mathrm{~mm}$ olacak şekilde oyuklar açılmıştır. Hazırlanan yığma taşlar deney düzeneğine yerleştirilerek, kayma yüklerini elde etmek amacıyla kenet elemanları hidrolik pompa yardımıyla yukarı doğru çekilmiştir. Deney sonucunda numunelerin maksimum kayma yükleri ve yapmış oldukları yer değiştirmeler tespit edilmiştir.
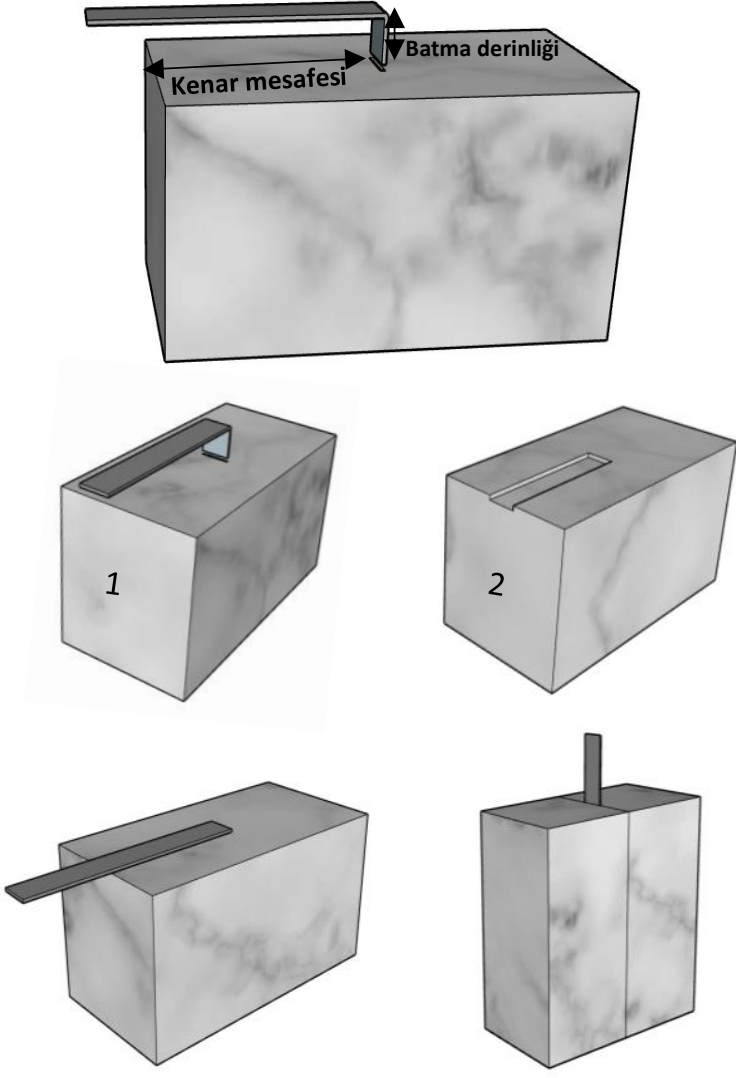

Şekil 4. Kenetin yığma taşların arasına yerleştirilmesi.

\section{Kenet Modellerin Sonlu Elemanlar Yöntemiyle Analizi}

Çalışmada kenet batma mesafesinin, taşın kayma dayanımına etkisi incelenmiştir. Deneysel olarak test edilen kenet modellerin LUSAS analiz programı kullanılarak sayısal analizi yapılmıştır. Çizelge 4'de belirtildiği gibi sayısal analizde taşın elastisite modülü $4000 \mathrm{MPa}$, Poisson oranı 0,2 ; kenetin elastisite modülü $203704 \mathrm{MPa}$, poisson oranı 0,3 olarak ele alınmıştır. Deneysel çalışmalara göre deney numunelerinin nonlinear (doğrusal olmayan) davranış sergilediği gözlemlenmiştir. Makro modelleme ele alınarak elasto-plastik davranışını temsil eden Drucker-Prager kriteri uygulanmıştır. Drucker- Prager kriterinde önemli olan, kohezyon (c) ve içsel sürtünme açısı $(\varphi)$ parametreleridir (Tanriverdi, 2020).

Sayısal analizde kenetlerde, genellikle metal elemanlar için uygulanan von Misses kriteri kullanılmıştır. Kriterin gerilme etkisi Denklem 2 ile ifade edilmektedir. von Mises kriterinin gerilme meridyenleri ve deviatorik düzlemdeki akma yüzeyleri Şekil 5'de verilmiştir.

$$
f=\sqrt{J_{2}}-k=0
$$


Burada $k$ pozitif malzeme sabiti, $J_{2}$; deviatorik gerilme tansörünün ikinci invaryantını göstermektedir.

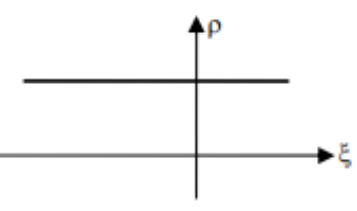

(a)

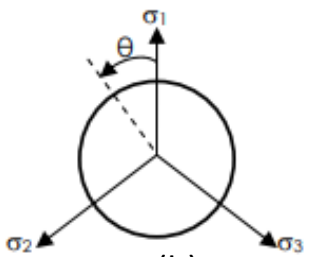

(b)
Şekil 5. von Mises kriterinin a) gerilme meridyeni, b) deviatorik düzlemdeki akma yüzeyleri (Dede, 2009).

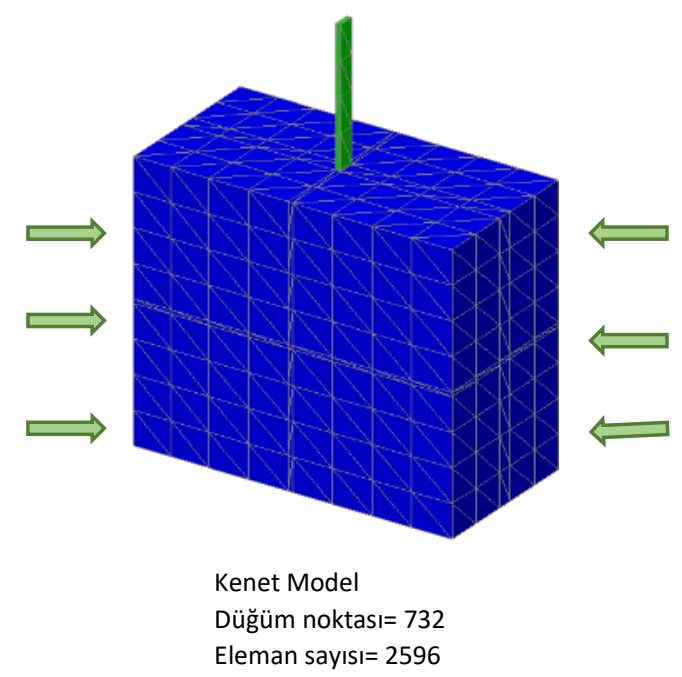

Şekil 6. Kenetli modelin analizde kullanılan düğüm noktası ve eleman sayısı.

Şekil 6'da kenetli modelin sonlu elemanlar analizinde kullanılan düğüm noktası ve eleman sayısı verilmiştir. Kenet modelin düğüm noktası sayısı 732, eleman sayısı ise 2596'dır. Modelin x doğrultusunda ötelenmeleri sabitlenmiştir. Sayısal modelde her düğüm noktasında 3 adet serbestliği bulunan 10 düğüm noktalı 3 boyutlu dörtyüzlü (tetrahedral) sonlu elemanlar kullanılmıştır.

Analiz çalışmasında taşın $\theta$ (içsel sürtünme açısı) ve c (kohezyon) parametreleri için $\theta=25^{\circ}-35^{\circ}$ ve $\mathrm{c}=2,80-3,70 \mathrm{MPa}$ değerleri dikkate alınmıştır (Doran,2003). Kenetin elastisite modülü 203704 $\mathrm{MPa}$, poisson oranı 0,3 olarak ele alınmıştır (Çelik, 2020).
Çizelge 4. Analizde kullanılan malzemelerin özellikleri ve değerleri

\begin{tabular}{cll}
\hline Malzemeler & Özellikler & Değer \\
\hline \multirow{2}{*}{ Taş } & Elastisite Modulü (MPa) & 4000 \\
& Poisson Oranı & 0.2 \\
& Kohezyon (MPa) & 2.5 \\
& Çsel Sürtünme Açısı & 25 \\
& Sürtünme Geriliminin Eğimi & 0.0 \\
& Plastik Şekil Değiştirme & 0.0 \\
& Elastisite Modulü (MPa) & 0.001 \\
\hline \multirow{2}{*}{ Kenet } & Poisson Oranı & 203704 \\
& Tek Eksenli Akma Gerilmesi (MPa) & 275 \\
& Çekmede Pekleşme Eğimi & 212.1 \\
& Plastik Şekil Değiştirme & 1.0 \\
& &
\end{tabular}

\section{Bulgular ve Tartışma}

Şekil 7'de deney sonucunda kenetli modellerin görünümü ve sayısal modellerin maksimum yük altında yapmış oldukları deplasman ve çekme gerilmesi dağılımı verilmiştir. Deney ve analiz sonuçlarından elde edilen yük-deplasman grafikleri ise Şekil $\mathbf{8}^{\prime}$ de gösterilmiştir. Deney ve analiz sonuçları doğrultusunda 20 mm'lik model diğer modellere göre daha az yük taşımıştır. Analiz sonucunda batma derinliğinin taşın kenarına olan mesafesi $20 \mathrm{~mm}$ ve $40 \mathrm{~mm}$ olan modellerde çekme gerilmeleri birbirine yakın çıkmıştır. Aynı şekilde kenetin batma derinliğinin taşın kenarına olan mesafesi $60 \mathrm{~mm}, 80 \mathrm{~mm}$ ve $100 \mathrm{~mm}$ olan modellerin çekme dayanımları da birbirlerine oldukça yakındır. Deney ve analiz sonuçlarında elde edilen yükdeplasman grafikleri incelendiği zaman kenetin taşın kenarına olan mesafesi $60 \mathrm{~mm}, 80 \mathrm{~mm}$ ve $100 \mathrm{~mm}$ olan modeller birbirine yakın davranış sergilerken 40 $\mathrm{mm}$ olan model ise farklı davranış sergilemiştir. Şekil 7 'den de görüldüğü gibi kenetin batma derinliğinin taşın kenarına olan mesafesi azaldıkça, kenetin taş üzerine verdiği hasar artarak daha büyük deformasyonlara neden olmuştur. 


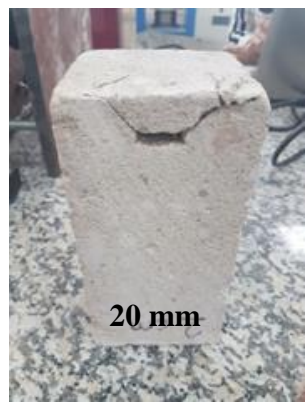

(a) $20 \mathrm{~mm}$ 'lik deney numunesi

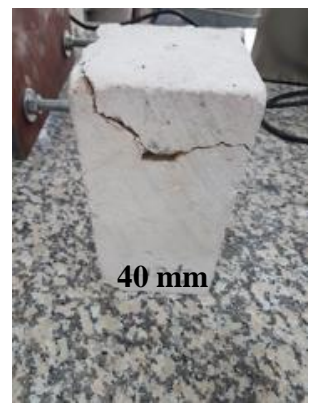

(b) 40 mm'lik deney numunesi

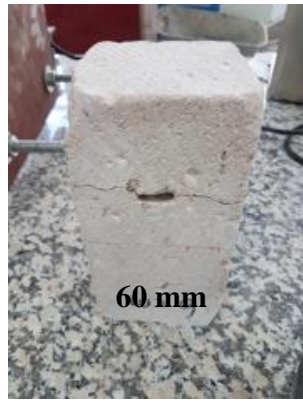

(c) $60 \mathrm{~mm}$ 'lik deney numunesi

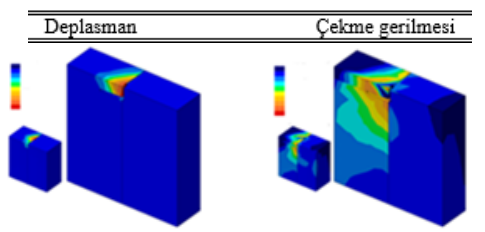

Max Deplasman: 0,059 mm Maksimum Çekme Gerilmesi: 0,258 MPa

(d) 20 mm'lik analiz modeli

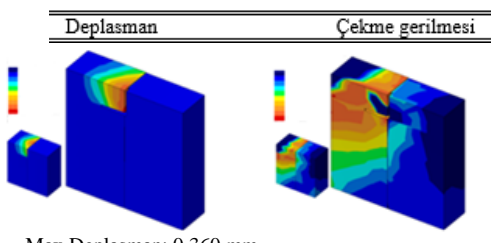

Max Deplasman: 0,360 mm Maksimum Çekme Gerilmesi: 0,299 MPa

(e) 40 mm'lik analiz modeli

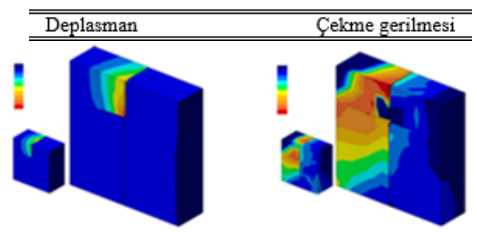

Max Deplasman: 0,172 mm Maksimum Çekme Gerilmesi: 0,314 MPa

(f) $60 \mathrm{~mm}$ 'lik analiz modeli

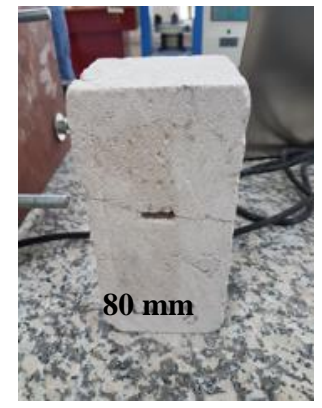

(g) $80 \mathrm{~mm}$ 'lik deney numunesi

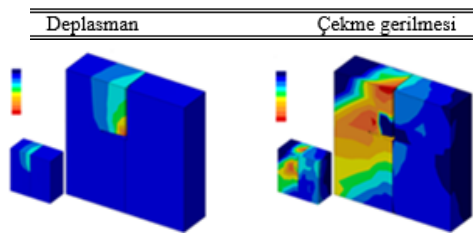

Max Deplasman: 0,116 mm

Maksimum Çekme Gerilmesi: 0,311 MPa

(j) $80 \mathrm{~mm}$ 'lik analiz modeli

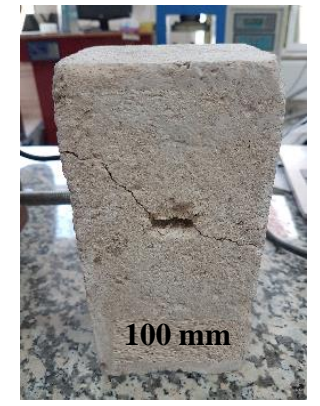

(h) $100 \mathrm{~mm}$ 'lik deney numunesi

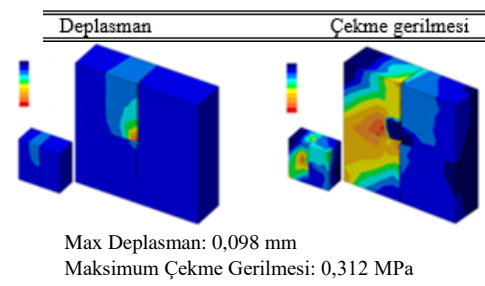

(k) $100 \mathrm{~mm}$ 'lik analiz modeli

Şekil 7. Deney ve sonlu eleman analiz sonuçları. 


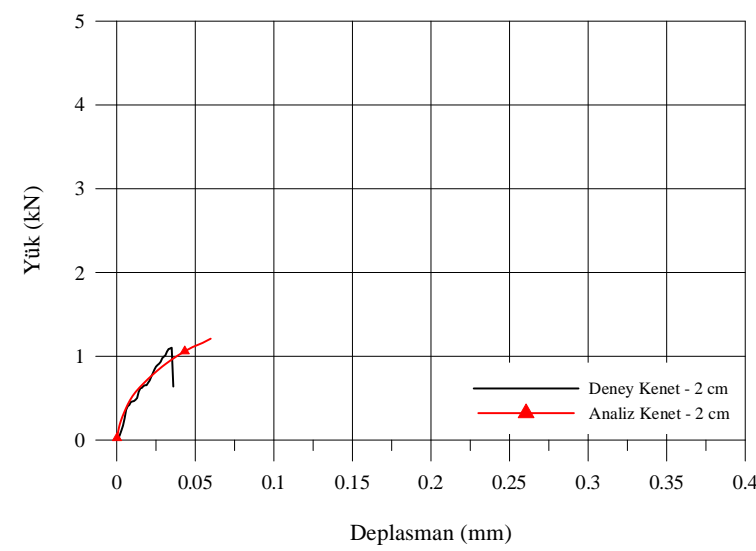

(a) $20 \mathrm{~mm}$ 'lik numuneler

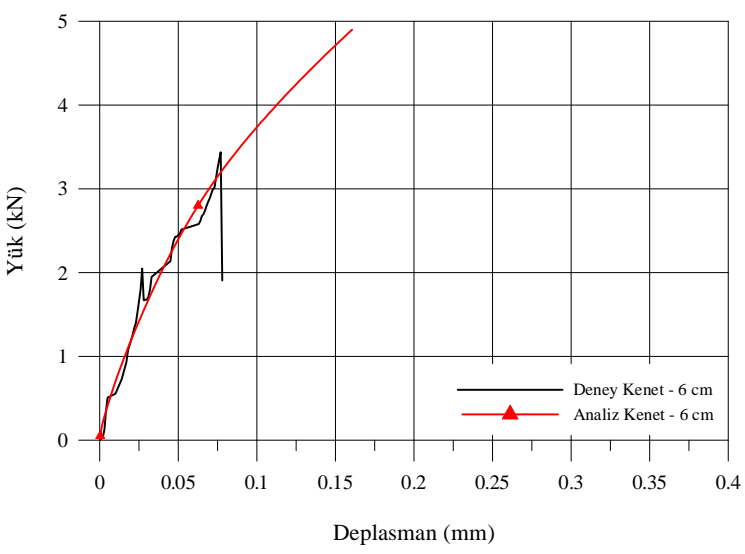

(c) $60 \mathrm{~mm}$ 'lik numuneler

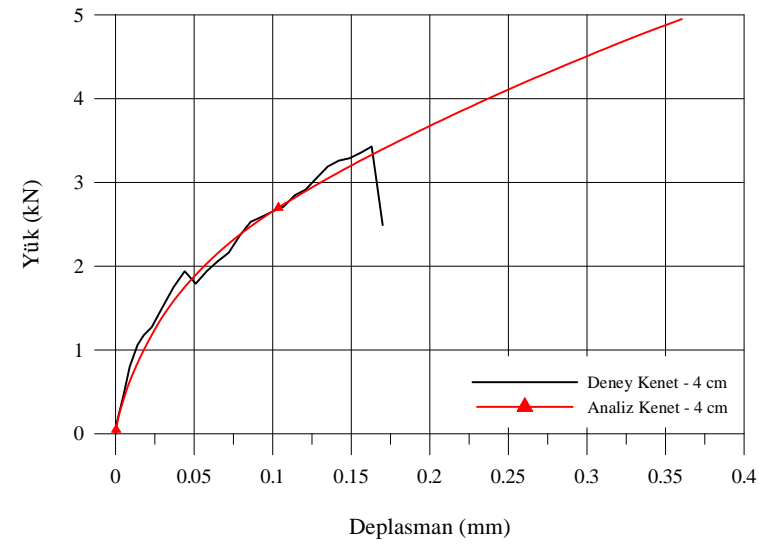

(b) $40 \mathrm{~mm}$ 'lik numuneler

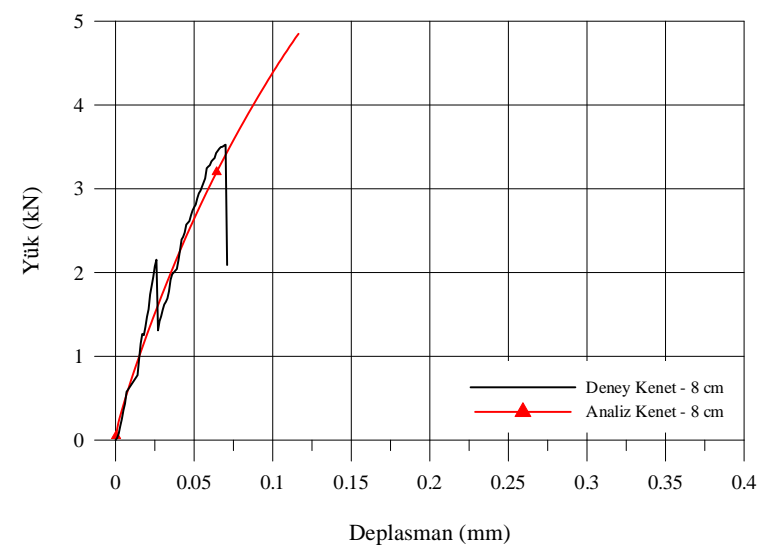

(d) 80 mm'lik numuneler

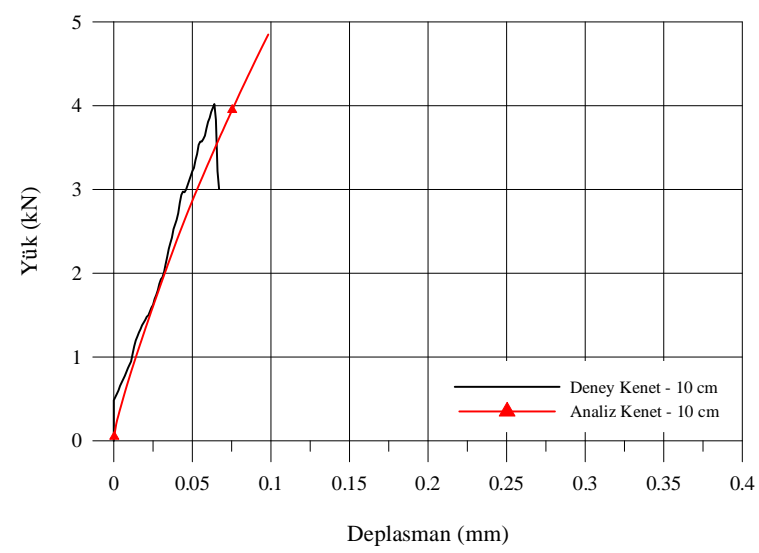

(e) 100 mm'lik numuneler

Şekil 8. Deney sonuçları ve sonlu eleman analiz sonuçlarının karşılaştırılması.

\section{Sonuçlar}

Zamanla tarihi yapılar, zemin özelliklerinin yetersiz oluşu, doğal afetler, insanlardan kaynaklı sebepler, hatalı malzeme kullanımı, doğal etkenler gibi çeşitli sebeplerden dolayı hasarlara uğramaktadır. Bu hasarların giderilmesi için tarihi yapılarda onarım ve güçlendirme gibi restorasyon çalışmaları yapılmaktadır. Tarihi yapılarda restorasyon çalışmalarında yapıların özellikle dayanımını artırabilmek amacıyla kenet zıvana gibi metal bağlantı elemanları kullanılmaktadır. Onarım ve güçlendirme çalışmalarında kenet, zıvana gibi elemanların tasarımını, nasıl uygulanacağını bilmek oldukça önemlidir. Bu çalışmada da kenetin batma derinliğinin taşın kenarına olan mesafesinin taşın kayma dayanımını nasıl etkilediği deneysel ve numerik olarak incelenmiştir. 
Deneysel çalışma değişken olarak alınan kenetin batma derinliğinin taşın kenarına olan mesafesini incelemek amaciyla her bir modelden 3 adet toplamda 15 adet model üretilerek yapılmıştır. Her bir deneysel modelin sayısal modellemesi de yapılarak deney ve analiz sonuçları karşılaştırılmıştır. $\mathrm{Bu}$ çalışmalardan elde edilen sonuçlar aşağıda maddeler halinde verilmiştir.

- Bağlantı elemanı olarak kullanılan kenetin taşın üzerine etki ettiği yüzey alanı azaldığı için, kenetin batma derinliğinin taşın kenarına olan mesafesi $20 \mathrm{~mm}$ olan modelde kayma yükü diğer modellere göre daha az olmuştur.

- Kenetin batma derinliğinin taşın kenarına olan mesafesi $60 \mathrm{~mm}, 80 \mathrm{~mm}$ ve $100 \mathrm{~mm}$ olduğu zaman modellerin göstermiş oldukları davranışlar birbirine oldukça yakın çıkmıştır. 40 mm'lik model diğer modellere göre daha sünek bir davranış sergilemiştir.

- Yapılan çalışma sonucunda kenetin batma derinliğinin taşın kenarına olan mesafesinin 100x100×200 mm $\mathrm{mm}^{3}$ boyutundaki taşlar için minimum $40 \mathrm{~mm}$ olması gerektiği belirlenmiştir. Farklı boyutlardaki taşlar içinde bu çalışmadan elde ettiğimiz davranışlara benzer sonuçların ortaya çıkacağı düşünülmektedir.

- Deneysel ve numerik çalışmalar sonucunda kenetin batma derinliğinin taşın kenarına olan mesafesinin (h) taşın uzunluğuna (b) oranının (h/b) 0,2 değerinden küçük olmaması sonucuna varılmıştır.

- Bu çalışma, ileride yeni yapılabilecek han, hamam, cami gibi yapıların ya da onarım ve güçlendirilmesi gereken tarihi yapılarda kenetlerin nasıl uygulanması konusunda iyi bir referans olacaktır. Kenet gibi dayanımı arttıran bir diğer metal bağlantı elemanı olan zıvana çaplarının taş bloklar veya yığma duvarlar üzerine etkileri araştırılması gereken bir başka konu olarak önerilecektir.

\section{Kaynaklar}

Akçaözoğlu, K. ve Akçaözoğlu, S., 2017. The effect of elevated temperature on the lightweight concrete produced by expanded clay aggregate and calcium aluminate cement. Bilge International Journal of Science and Technology Research, 1, 2, 59-70.

Baranaydın, F., 2020. Ephesos St. Jean kilisesi kiborion sütunu 1963 yılı restorasyonuna güncel bir yaklaşım. AMisOS, 5, 8, 31-50.

Çelik, T., 2020. Tarihi cami kubbelerinde güçlendirme yöntemlerinin deneysel metotlarla incelenmesi. Doktora Tezi, Aksaray Üniversitesi, Fen Bilimleri Enstitüsü, Aksaray, 246.

Dede, T. ve Ayvaz, Y., 2009. Betonun Doğrusal Olmayan Analizinde Kullanılan Kriterler. Firat University Journal of Engineering, 21, 2, 151-159.

Doran, B., 2003. Elastic-plastic analysis of R/C coupled shear walls: Theequivalent stiffness satio of the tie elements. Journal of the Indian Institute of Science, 83, 87-94.

Karabork, T. ve Kocak, Y., 2014. New metal connectors developed to improve the shear strength of stone masonry walls. Struct. Eng. Mech, 50, 1, 121-135.

Kurugöl, S. ve Küçük, S.G., 2015. Tarihi eserlerde demir malzeme kullanım ve uygulama teknikleri. 5. Tarihi Eserlerin Güçlendirilmesi ve Geleceğe Güvenle Devredilmesi Sempozyumu, Erzurum, 521-536.

Lusas, Finite element analysis software products, Finite Element System FEA Ltd, 2020.

Smoljanovic, H., Nikolic, A. ve Zivaljic, N., 2015. A finitediscrete element model for dry stone masonry structures strengthened with steel clamps and bolts. Eng. Struct, 90, 117-129.

Tanriverdi, Ş., Çelik, T., Ural, A. ve Firat F.F., 2018. Investigation of the effect of the clamps with different Immersion depth on the masonry wall's behaviour. International Conference on Science and Technology - ICONST, 186-193.

Tanrıverdi, Ş., 2020. Taş kubbelerde pencere boşluğunun ve kasnak yüksekliğinin davraniş ve dayanim üzerine etkisinin incelenmesi. Doktora Tezi, Aksaray Üniversitesi, Fen Bilimleri Enstitüsü, Aksaray, 157.

TS EN 772-6, 2004. Kâgir birimler-deney metodları-bölüm 6: Beton kâgir birimlerin eğilmede çekme dayanımının tayini. Türk Standartları Enstitüsü, Ankara. 
TS EN 1052-3, (2004). Kâgir-deney metodları-bölüm 3: Başlangıç kayma dayanımının tayini, Türk Standartları Enstitüsü, Ankara.

TS EN 772-1+A1, 2015. Kâgir birimler-deney yöntemleribölüm 1: Basınç dayanımının tayini. Türk Standartları Enstitüsü, Ankara.

TS EN ISO 6892-1, (2020). Metalik malzemeler-çekme deneyi-bölüm 1: Ortam sıcaklığında deney metodu, Türk Standartları Enstitüsü, Ankara.

Ural, A. Ve Kara, M.E., 2015. Kenet ve zıvanaların yığma duvarların kesme (kayma) davranışına etkisi. 5. Tarihi Eserlerin Güçlendirilmesi ve Geleceğe Güvenle Devredilmesi Sempozyumu, Erzurum, 537-548.

Uslu, S. 2013. Tarihi yığma yapılarda kullanılan metal bağlantı elemanlarının deneysel metotlarda incelenmesi. Yüksek Lisans Tezi, Aksaray Üniversitesi, Fen Bilimleri Enstitüsü, Aksaray, 101.

Vermeer, P.A. ve Borst De, R., 1984. Non-associated plasticity for soils, concrete and rock. Heron, 29, 3, 364.

Yılmaz, M., ve Tek, S. 2018. Antalya Yivli Minare ve Camisinin restorasyon, güçlendirme ve zemin etüt çalışmaları. MASROP E-Dergi, 12, 1, 49-72. 